\title{
WHEY IN INFANT-FEEDING
}

STUDIES OF INFANT-FEFIING：FIFTH PAPER *
A. W. BOSWORTH, GENEVA, N. Y.
I. BOWDITCH, AND BOSTON
B. H. RAGLE
BOSTON

\section{INTRODUCTION}

The investigations of Osborne and Mendel ${ }^{1}$ have shown the important part taken by the whey salts in the growth and development of the young rat, and Holt, Levene and others ${ }^{2}$ have shown that a proper adjustment of the relation between the amount of whey and some of the other constituents present in infant-foods is quite necessary in order to prevent disturbances in the normal metabolism and physical condition of artificially fed infants. It has, therefore, become necessary, in our studies of infant-feeding, for us to know more about the significance of whey, especially in connection with the treatment of certain types of infectious diarrhea, fat intolerance and regulation of feeding, and the investigations reported here are some of the results obtained by us in this connection.

The baby used for this investigation was of a rather happy disposition and had been used by us, some months previous to the present observation, for other metabolism work. He had been discharged from the hospital after a period of feeding regulation, and was readmitted on July 9, 1913, suffering from intestinal indigestion due to overfeeding.

\section{METABOLISM OBSERVATION}

The investigation began with the admission of the baby to the hospital on July 9 and may be divided into six periods as indicated.

* Submitted for publication Dec. 14, 1914.

* The expense of this investigation was defrayed by the Boston Floating Hospital, Boston, Mass. The chemical work was done in the Biochemical Laboratory of the Harvard Medical School, Boston, Mass. We wish to thank Dr. Otto Folin for his courtesy in extending this privilege to us.

* Bowditch, H. I. and Bosworth, A. W.: Casein in Infant-Feeding: Experiments in Exact Percentages, Am. Jour. Dis. Child., December, 1913, p. 394; Rules for Calculating the Approximate Composition of Milk from the Specific Gravity and Percentage of Fat as Determined by the Babcock Method, ibid., March, 1914, p. 244. Bosworth, A. W., and Van Slyke, L. L.: Why Sodium Citrate Prevents Curdling of Milk by Rennin, ibid., April, 1914, p. 298. Bosworth, A. W., Bowditch, H. I., and Ragle, B. H.: Casein in Infant-Feeding: The Preparation of Dry Powdered Paracasein, ibid., August, 1914, p. 120.

1. Publication No. 156 of the Carnegie Institute.

2. Holt, Levene et a1.: Am Jour. Dis. Child., 1912, iv, 265. 
First Period, 6 p. m. July 9 to 6 p. m. July 12

From 6 p. m. July 9 until 10 a. m. July 11 (forty hours) the child received only sterile water. From $10 \mathrm{a}$. m. July 11 to $6 \mathrm{p}$. m. July 12 (thirty-two hours) the food consisted of a mixture of 840 c.c. of whey, 420 c.c. of breast-milk and 420 c.c. of water and was divided into ten feedings. The child was on the metabolism frame during all three days.

The high output of uric acid, creatinin and creatin during the fast indicates a high endogenous metabolism and is followed by a higher excretion of these substances on the administration of food; the excretion of nitrogen, however, is lowered during the first day following the fast, indicative of a replacement of the nitrogen lost during the endogenous metabolism of the fast. During the fast the chlorin excreted was very small in amount, and both indican and acetone were detected in the urine. The child also had an acetone breath.

\section{Second Period, 6 p. m. July 12 to 6 p. m. July 22}

A period during which the food was changed several times in order to find a mixture suitable for the child. The child was not on the metabolism frame and no analytical data were secured during this period.

Third Period, 6 p. m. July 22 to 6 p. m. July 26

The child had recovered from his intestinal trouble and was receiving the following formula: Fat, 1 per cent.; sugar, 6 per cent.; protein, 2 per cent.

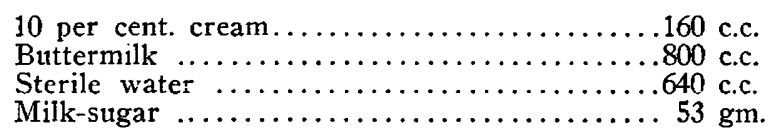

Seven feedings of 210 c.c. each every twenty-four hours. Approximately 637 calories or 145 calories per kilo body weight.

As he seemed to be in good condition and gaining in weight on this food, he was placed on the metabolism frame at $6 \mathrm{p}$. m. July 22. During this period he continued to receive the food indicated above and the urine and feces were collected and examined in order to furnish data representing his normal nitrogen metabolism. During this period the body weight increased $165 \mathrm{gm}$., and average of $41.2 \mathrm{gm}$. per twenty-four hours. He was well in every respect.

Fourth Period, 6 p. m. July 26 to 6 p. m. July 29

The child was not on the frame during this period but received the same food given in the preceding period. No macroscopic or microscopic evidence of fat, carbohydrate or protein indigestion was found.

\section{Fifth Period, 6 p. m. July 29 to 6 p. m. August 7}

The child was again placed on the frame and the food received was made up according to the following formula: Fat, 1 per cent.; sugar, 6 per cent.; protein, 2 per cent.

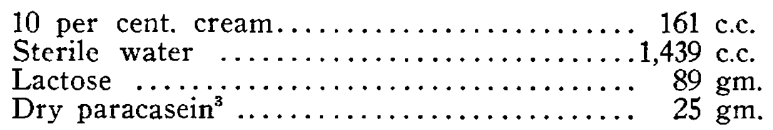

Seven feedings of 210 c.c. each per twenty-four hours.

This mixture contained about the same amounts of fat, sugar and protein as the mixture given in the two preceding periods. The amount of protein ingested in twenty-four hours was less than in the case of the food made with

3. A method of preparing dry powdered paracasein has been given in a previous paper, A m. Jour. Dis. Child., August, 1914, p. 120. 
buttermilk. This was due to the fact that it was almost impossible to manipulate the feeding-bottles so that all the paracasein was removed with the liquid portion of the food.

The inorganic salts were very much decreased in this mixture. In the preceding periods the mixtures fed contained the salts carried in the 160 c.c. of cream and the 800 c.c. of buttermilk. In the present case all the inorganic salts were derived from the 161 c.c. of 10 per cent. cream. The response to this decrease in the inorganic salt intake is shown in the lower figures obtained during this period for sodium chlorid, phosphates and acidity. The food contained $0.116 \mathrm{gm}$. of sodium chlorid per twenty-four-hour quantity while the amounts excreted dropped from $0.326 \mathrm{gm}$. the first day to nothing on the eighth and ninth days, chlorin again appearing on the tenth day (the first day of the sixth period) even with a reduction in the chlorin intake on that day. This small chlorin excretion, zero for two days even, was not accompanied by any signs of physical discomfort.

During this period the body weight increased $120 \mathrm{gm}$. , an average of 13.3 gm. per twenty-four hours.

\section{Sixth Period, 6 p. m. August 7 to 6 p. m. August 14}

From $6 \mathrm{p}$. m. August 7 and during this period the food given to the child was made according to the following formula: Fat, 2 per cent.; sugar, 6 per cent., protein, 2 per cent.

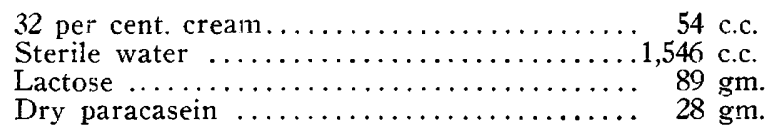

Seven feedings of 210 c.c. each per twenty-four hours.

This decreased the inorganic salts again and made the chlorin intake per twenty-four hours equal to $0.033 \mathrm{gm}$. of sodium chlorid, and the amounts excreted dropped from $0.148 \mathrm{gm}$. to $0 \mathrm{gm}$. on the fifth, sixth and seventh days. The child showed no particular discomfort as a result of this rather prolonged confinement on the metabolism frame, but on account of the loss of body weight it was thought best to discontinue the collection of urine and feces and remove the child from the frame at $6 \mathrm{p} . \mathrm{m}$. August 14 .

\section{GENERAL DISCUSSION}

In connection with the table which gives the result of our daily examination of the urines, we desire to call attention to the following pionts :

The acidity of the urines and the amounts of phosphates present decreased with the decrease in the amounts of whey ingested. This was to be expected as all the inorganic phosphates ingested were contained in the whey or cream used to make up the formulas. The amounts of organic phosphorus ingested were practically the same through all the periods.

The elimination of chlorin-free urine for two- and three-day periods without symptoms of any nature is worthy of note.

A very marked increase in the ammonia output during the sixth period of the experiment is noticeable. During the fifth period the whey in the 161 c.c. of 10 per cent. cream furnished considerable neutral salts of organic acids (citrates, albuminates, etc.), the bases of 


\begin{tabular}{|c|c|c|c|c|c|}
\hline \multicolumn{2}{|c|}{ 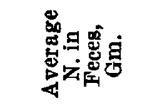 } & & $\mid$ & 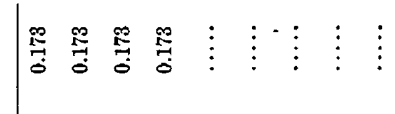 & $\vdots \vdots$ \\
\hline \multirow{11}{*}{ 善 } & 憲息 & 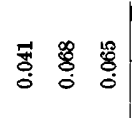 & 害 & 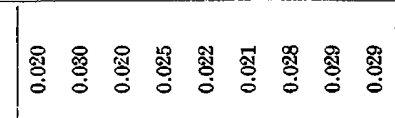 & 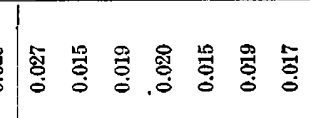 \\
\hline & 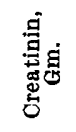 & 爱器管 & : & 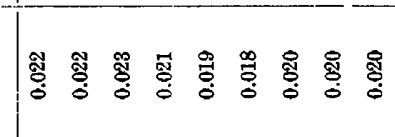 & 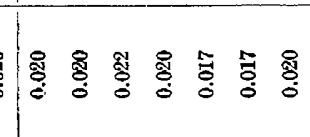 \\
\hline & 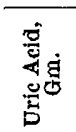 & 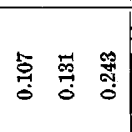 & 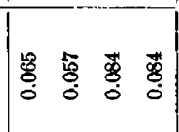 & 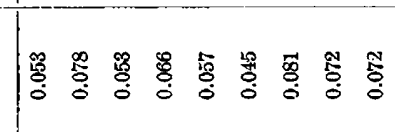 & 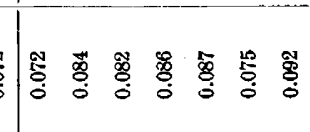 \\
\hline & 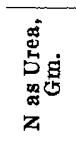 & 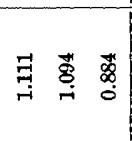 & 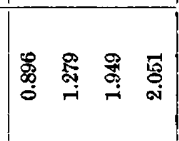 & 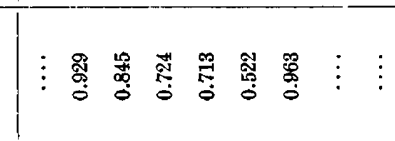 & 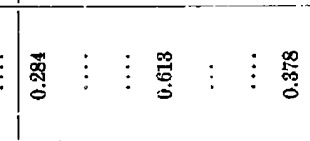 \\
\hline & 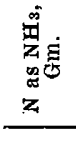 & 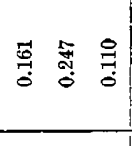 & 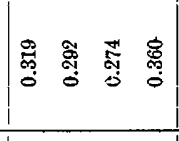 & 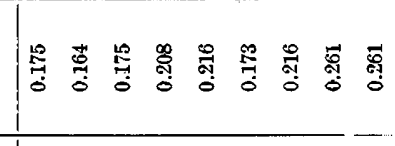 & 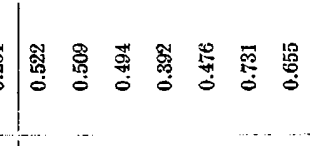 \\
\hline & 畜: & 善密尊 & 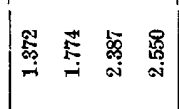 & 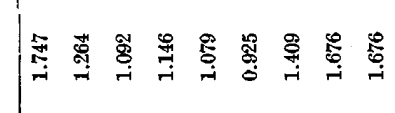 & 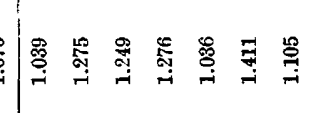 \\
\hline & 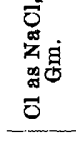 & 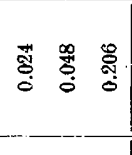 & 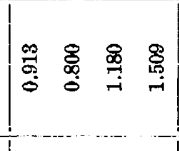 & 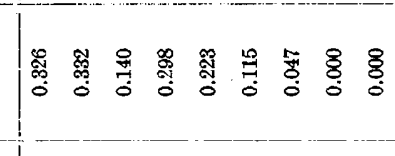 & 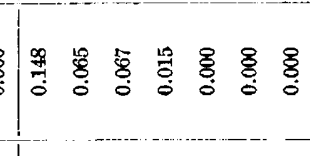 \\
\hline & 密 & 营落 & 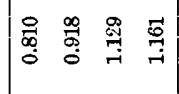 & 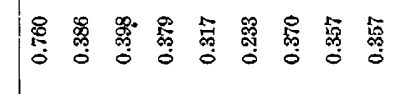 & 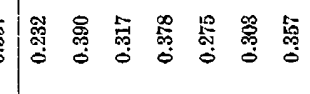 \\
\hline & 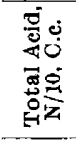 & 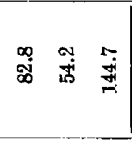 & 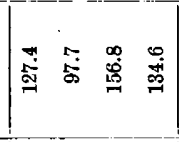 & 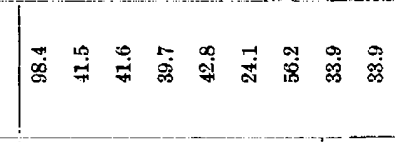 & $\mid$ \\
\hline & 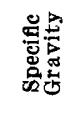 & 总䒯 & 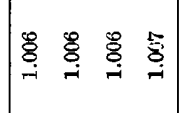 & 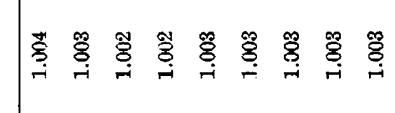 & 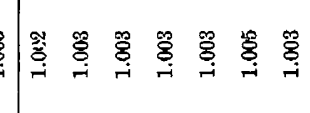 \\
\hline & ن. & 总果 & 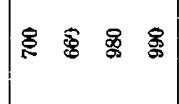 & 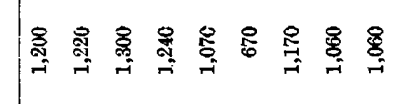 & 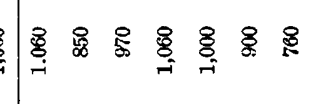 \\
\hline \multicolumn{2}{|c|}{ 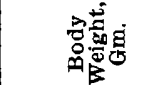 } & 叠 & 要 $\quad \vdots \quad \vdots \quad \vdots$ & 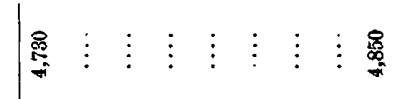 & $\begin{array}{lllllll}\vdots & \vdots & \vdots & \vdots & \vdots & \vdots & \vdots \\
\end{array}$ \\
\hline & & 莣 & $\infty$ & $\infty * \infty$ & $\infty \frac{\infty}{\infty}$ \\
\hline
\end{tabular}


which could be used to neutralize the acid bodies eliminated in the urine. During the sixth period, however, the intake of such basecarrying substances was much reduced, and sufficient bases were not ingested to neutralize the acid bodies eliminated in the urine. This resulted in an immediate increase in the amount of ammonia in the urine with a corresponding decrease in the urea. For the twenty-four hours ending at $6 \mathrm{p}$. m., August 7, the urine contained $0.261 \mathrm{gm}$. of nitrogen present as ammonia, and for the twenty-four-hour period ending at 6 p. m., August 8 , the first day of the reduction of the intake of the salts to the lowest figure, the urine contained $0.522 \mathrm{gm}$. of nitrogen in the form of ammonia, an increase of 100 per cent. in one day.

It will be noticed that only a small part of the ammonia is necessary to neutralize the phosphates. Just what the nature of the acid bodies is we are not able to state. We did not detect the presence of acetone bodies in the urine at any time during this period.

The amounts of creatinin and creatin excreted during the fasting period were much above the normal as would be expected. During the other three periods the creatinin figures are strikingly uniform.

During the third period, when the food contained an excess of all constituents, the child increased in body weight an average of $41.2 \mathrm{gm}$. per twenty-four hours and the creatin output averaged $0.028 \mathrm{gm}$. per day. In the fifth period when the whey had been reduced to the amount carried in 161 c.c. of 10 per cent. cream, the average daily increase in body weight was reduced to $13.3 \mathrm{gm}$. and the average daily creatin excretion was $0.025 \mathrm{gm}$. In the sixth period there was an average daily decrease in body weight of $48.6 \mathrm{gm}$., and the average daily excretion of creatin was $0.019 \mathrm{gm}$. with a daily fluctuation giving figures between 0.027 and $0.015 \mathrm{gm}$.

The child received an abundance of fat, sugar and protein during all of the experiment; the whey constituents being under observation were of course the only variable. The observation seems to indicate, therefore, that the amount of whey received during the fifth period was not sufficient to promote the maximum growth, yet large enough to prevent an actual cessation of growth, while during the sixth period the amount of whey received was so small that growth was stopped and the body lost in weight. It might be claimed that the long confinement on the metabolism frame was responsible for the loss in weight during the last period, but in answer to this we can say that the baby was of exceptionally happy disposition, showed no signs of discomfort during all the investigation and was very carefully watched and cared for. We carried the observation as far as was advisable with a human subject, and feel that we have confirmed in this case the work of Osborne and Mendel in which they demonstrated the 
necessity of whey salts to promote growth of the young when fed on pure materials - fats, carbohydrates and protein.

The investigation would also seem to bear out the theory that creatin excretion is in some way involved in growth and also to offer an explanation of the fact observed by others that the creatin excretion of growing infants varies from day to day. An infant normally grows quite rapidly, increasing several grams per day in body weight. If the food taken and retained during any day or series of days is not sufficient to meet all the demands of maximum growth, growth will fluctuate and a corresponding fiuctuation in the creatin elimination will result.

This paper constitutes a report of a part of a series of investigations which is being conducted in connection with the regular clinical work of the Boston Floating Hospital. 